\title{
Male breast cancer - how to treat?
}

\author{
E. D. Rossmann ${ }^{a, b, \star}$, A. Liljegren ${ }^{a, b, \star}$, J. Bergh ${ }^{a, b}$ \\ ${ }^{a}$ Department of Oncology, Radiumhemmet, Karolinska University Hospital, Stockholm, Sweden; \\ ${ }^{b}$ Department of Oncology-Pathology, CancerCenterKarolinska, Karolinska Institute, Stockholm, Sweden
}

\begin{abstract}
Treatment principles of breast cancer in males are derived from studies performed among females, while the low incidence in males has so far precluded such studies. The therapy recommendations for males therefore lack the solid evidence, frequently present for females with breast cancer. The primary breast cancer diagnosis in males is not infrequently in stage III/IV and at higher age, thereby requiring multiprofessional and multimodal management including preoperative therapy and adjuvant therapies based on the tumour's biological characteristics and the clinical circumstances. The majority of male breast cancer tumours are oestrogen-receptor positive and adjuvant/neoadjuvant tamoxifen is therefore recommended, surgery is frequently radical mastectomy and adjuvant radiotherapy should likely be used on wider indications. Chemotherapy should be considered both in the adjuvant and metastatic setting for receptor-negative cancers and for patients with biologically aggressive disease. Trastuzumab should be offered to patients with Her-2/neupositive disease, while the use of aromatase inhibitors is more uncertain due to differences in the hormonal environment in males.
\end{abstract}

Keywords: Breast cancer; Male; Treatment

\section{Introduction}

Male breast cancer (MBC) is a rare disease accounting for less than $1 \%$ of all breast cancer cases [1]. Due to the low incidence of the MBC, the aetiology and pathogenesis of the disease is not completely characterised and poorly understood compared with breast cancer in females (FBC). This fact is well documented by ongoing debate regarding similarity vs. emerging clear differences of the breast carcinoma in males and females [1-5]. The diagnostic and therapy procedures are not well

*These authors contributed to the work equally.

Correspondence to: Eva Rossmann, MD, PhD, Department of Oncology, Radiumhemmet, Karolinska Institutet and University Hospital, Solna, S-171 76 Stockholm, Sweden. E-mail: eva.rossmann@karolinska.se; Tel: +46 517700 00; Fax: +468318327

Received: 24/07/07

Accepted: 26/07/07

BCO/646/2007/FO defined in MBCs. The probable reasons behind the frequent, late diagnoses presented at stages III or IV might be the low public awareness and neglected psychological aspect of the disease [6,7]. The rarity of the disease precludes large prospective randomised clinical trials. Therefore, the general treatment strategies for MBC extrapolates from clinical studies carried out in FBC and the optimal treatment principles remain to be established.

\section{Incidence and mortality}

Unlike the continuously increasing incidence for FBC, the incidence for MBC has been reported to rise or be stable over the last decades. In a population-based study from USA, a $26 \%$ increase of incidence for $\mathrm{MBC}$ has been found, from 0.86 to $1.08 / 100000$ population during the time period 1973-1998 [3]. Stable age-adjusted incidence 
trends during the years 1973-2000 were revealed in an analysis of incidence data derived from surveillance, epidemiology and end-result (SEER) database [8]. In line with this, a recent report from Sweden demonstrates a stable incidence for MBC about 0.66/100 000 during the years 1971-2007 [6].

The median age at diagnosis for MBC is found to be higher as compared to FBC with a unimodal peak distribution. The incidence has been found to culminate in males between the ages of 63 and 71 years according to various reports $[2,3,9]$.

Conflicting results have been published regarding prognostic factors and the clinical outcome of MBC as compared to FBC. The overall 5- and 10 -years survival rates in MBC are $63 \%$ and $41 \%$, respectively. Patients with $\mathrm{MBC}$ stage-by-stage fared statistically significantly worse compared to FBC [3]. However, these data are partly challenged by a recent study comparing 612 males and 2413 females from a veterans population with breast cancer, demonstrating a statistically significant worse outcome for MBC only in early-disease stages (stage I and II) [5]. Racial disparities with significantly shorter 5-year survival have been observed among black patients with $\mathrm{MBC}$ as compared to white patients with MBC $(66 \%$ and $90 \%$, respectively) [10].

\section{Risk factors for developing male breast cancer}

Men with BCRA-2 mutations are predisposed to develop breast cancer. On the contrary, BCRA-1 mutation does not seem to be a risk factor, although it has been described in affected men [11,12]. Many of the risk factors for $\mathrm{MBC}$ involve abnormalities in oestrogen (excess) and androgen (deficiency) balance. Testicular dysfunctions caused by anatomic and/or physiologic aetiology gives consistent association with elevated breast cancer development in men. Individuals with Klinefelter's syndrome (karyotype 47XXY) have an up to 50-fold increased risk for MBC. Furthermore, lifestyle and environmental factors such as alcohol, smoking, obesity, liver dysfunction, radiation to the breast and chronic exposure to heat have been found to correlate with increased risk for MBC [7]. Other reported factors are family history and Jewish ancestry (reviewed in [2], Table 1).

\section{Diagnosis, clinical and tumour characteristics}

Approximately $75 \%$ of MBC cases clinically present with a painless subareolar lump in the breast tissue. In rare cases, pain associated with lump, nipple involvement, bleeding from the nipple, ulceration or axillary nodal metastasis without palpable breast lump could be the first sign of the disease [1].

Generally, males with breast cancer differ in presenting characteristics as compared to females such as higher age at the time of diagnosis, more advanced disease stage, larger tumour size and more frequent lymph node involvement [3].

The diagnosis of MBC should be based on the combination of clinical assessment, mammography/ultrasound and morphology verification (a fine-needle biopsy or a core biopsy for histopathology) $[6,7,13]$.

The predominant histological type is invasive ductal carcinoma accounting for $90 \%$ of $\mathrm{MBC}$ cases [13]. Hormone receptor positivity is more frequent in $\mathrm{MBC}$ than in FBC. In a large populationbased cohort comparing 680 males with 119732 females, $90.6 \%$ of MBC were oestrogen-receptor (ER) positive and $81 \%$ progesterone (PR) positive, compared with $76 \%$ and $67 \%$ in females, respectively [3]. This is in line with another recent study describing a significantly higher ER and PR positivity in males (95\% and $85 \%$, respectively) than in females (82\% and $79 \%)$ [5].

\section{Primary local and loco-regional therapies for male breast cancer}

The first-choice treatment modality of MBC is surgery, either in the primary setting for early/localised

Table 1. A selection of risk factors in male breast cancer and the corresponding relative risk of increased risks for men.

\begin{tabular}{lll}
\hline Risk factor & Relative risk/increase & High-risk group \\
\hline Family history & $2,5 \mathrm{RR}$ & MBC in first-degree relative \\
Klinefelter's syndrome & $20-50$-fold increase & People with Klinefelter's syndrome \\
Obesity & $2,3 \mathrm{RR}$ & Very overweight \\
Testicular abnormality & $2-12-$ fold increase & Mumps in $>20$ years, cryptorchidism \\
Alcohol consumption & $1,16 \mathrm{RR}$ & $16 \%$ increase with every daily drink (10 g alcohol) \\
Liver cirrhosis & $3-4-$ fold increase & \\
Radiotherapy to the breast & $1,6-1,9 \mathrm{RR}$ & Treated for gynaecomasty \\
Age & & Elderly individuals with a peak incidence at 71 years \\
\hline
\end{tabular}


disease or following neoadjuvant therapy in locally advanced breast cancers. The modified radical mastectomy is the most commonly performed surgical procedure $[1,11,14]$. However, breast-conserving approaches with or without radiotherapy as well as more radical surgical procedures have also been used $[7,13]$. Surgical assessment of the axilla should be performed along with the primary surgery, either by sentinel node biopsy in clinically node-negative disease with small tumours $(\leqslant 2 \mathrm{~cm})$ or by axillary node dissection in node-positive cases [13].

Radiation is given aiming to reduce loco-regional recurrence, thus improving long-term impact on survival [15]. Males with tumours larger than $1 \mathrm{~cm}$ and/or all males with node-positive disease should receive postoperative radiotherapy as well as cases operated with breast-conserving surgery [16]. Nevertheless, it is mandatory to deliver threedimensionally planned radiotherapy aiming to minimise total heart doses [13].

\section{Neoadjuvant therapy}

In males with inoperable breast cancer (tumour ulceration, tumour fixation to thorax or advanced lymph node status), neoadjuvant treatment should be considered. The neoadjuvant treatment should be based on the tumour's biological characteristics and proof of invasiveness needs to be present before starting treatment. In females, neoadjuvant treatment has so far demonstrated similar survival expectations compared with the corresponding therapy given in the adjuvant setting [17-19]. The superior advantage of neoadjuvant therapies in males is that the effect of selected therapy can be followed in situ. The neoadjuvant treatment usually includes chemotherapy, aromatase inhibitors (Al) $[20,21]$ but trastuzumab may also be an option [22].

\section{Adjuvant therapy}

Most information on adjuvant treatment of MBC comprises retrospective case series analyses, which give conflicting findings on the benefit of adjuvant chemotherapy and hormonal therapy in male patients $[9,23-30]$.

\section{Hormonal treatment}

A majority, $85 \%$, of $\mathrm{MBC}$ is ER positive, and tamoxifen is generally considered as standard adjuvant therapy $[1,31]$. Due to scarcity of randomised trials evaluating tamoxifen in men, the relationship between ER positivity and survival benefit with tamoxifen is less clear in men than in women.
On searching in the literature, the number of men included in studies is low. In one study, which included 57 men, significant increased disease-free survival $(P=0.0368)$ and overall survival $(P=0.04)$ was found [9]. Similar results were found in another series with significant improvement in 5-year survival with $39 \%$ and $61 \%$ with and without $1-2$ year tamoxifen use, respectively [30]. The side-effects from tamoxifen are as for females: hot flushes, depression, weight gain, impotence and thromboembolic accidents [32].

\section{Aromatase inhibitors}

The Al anastrozole [33] and letrozole [34] have recently shown to be effective in the adjuvant setting among postmenopausal females giving prolonged disease-free survival compared to tamoxifen in large multicentre trials. Switching treatment to examestane after 2-3 years treatment with tamoxifen also improves disease-free survival [35]. Anastrozole given to young men (16 years) reduced the estradiol values by $50 \%$ and increased testosterone values by $41-61 \%$ [36], and letrozole (CGS 20267 ) reduced the estradiol values with $80 \%$ in males; thus, these drugs might be considered as potential therapeutic tools. The Al may be more efficient if the testicular function is down regulated, by either a surgical or medical orchidectomy [37]. The combined therapy with gonadal ablation by gonadotropin-releasing hormone $(\mathrm{GnRH})$ analogue such as gosereline and Al may give complete suppression of oestrogens but unfortunately also impairing quality of life due to reduced libido. However, there is no such data in the literature at present.

\section{Chemotherapy}

In males, there is an increased risk of higher toxicity from conventional chemotherapy and it is more common with medical contraindications due to higher mean age at breast cancer diagnosis [3].

Non-randomised, earlier and recent studies show that males with breast cancer and lymph node involvement will have a better prognosis if systemic adjuvant therapy is offered $[24,28,29,38-40]$. Different types of regimens have been used [41] including cyclophosphamide-methotrexate-5-fluorouracil (CMF) or anthracycline-based regimens, predominantly being 5-fluorouracil-adriamycincyclophosamide (FAC). In addition, taxanes have more recently been used, but conclusive data are lacking in MBC [1]. In one prospective study with CMF, 24 patients with stage II disease, was the 5 -year survival rate projected by actuarial means of 
80\% (95\% confidence interval: $74-100 \%)$ [38]. In a recent prospective study with a 20-year follow up of 31 patients treated with CMF, the overall survival at 10 years was $64.5 \%$, at 15 years $51.6 \%$ and at 20 years $42.4 \%$ [40]. In a retrospective study of 156 men, 51 men received systemic therapy of which $72 \%(n=23)$ were treated with anthracycline-based regimes. The hazards ratio $(\mathrm{HR})$ for time to recurrence was $0.7(\mathrm{Cl}: 0.42-1.17)$ and the $\mathrm{HR}$ for overall survival was 0.57 (Cl: $0.34-0.95)$ compared with those who did not receive any systemic therapy [39].

Although the reported studies are small and inconclusive, males with breast cancer and lymph node involvement and patients with endocrine unresponsive tumours should be offered adjuvant chemotherapy.

\section{Her-2/neu}

Her-2/neu overexpression in men with breast cancer varies from $9 \%$ to $29 \%$ in three main series, and one of the groups demonstrated a higher frequency of Her-2/neu-positive breast cancers in males compared with the findings in females [42-44]. Among 77 male patients, primary tumour in $29 \%$ were Her-2/neu positive as assessed by immunohistochemistry [44]. The high degree of positivity is likely due to the advanced tumour stage [45]. Based on the data from females, males with Her-2/neu-amplified breast cancers should be offered therapy with trastuzumab in both the adjuvant and metastatic setting based on the criteria established for females [46-48].

\section{Metastatic disease treatment}

The sites of metastases in men are similar to those in women and include bone, lung, liver, brain and others. The approach to the treatment of metastatic breast cancer is similar in male and female patients with breast cancer. Historically, a male with metastases from breast cancer was treated with different ablative surgical procedures: adrenalectomy, hypophysectomy and orchidectomy, which in historical series showed a $55-80 \%$ response rate [49]. These surgical procedures are rarely used today and have been replaced by additive hormonal therapies. There are data from females with breast cancer that primary tumours can be hormonal receptor negative and the relapse turns out to be negative and vice versa [50]. Similar data are reported in the Her-2/neu with inconsistency of Her-2/neu amplification in the primary tumour compared with the corresponding metastases [51]. Accordingly, it is recommended that at least one metastatic lesion should be biopsied to estimate Her-2/neu status, hormonal receptor status and proliferation. This procedure gives the opportunity to tailor the metastatic treatment therapy based on the tumour's biological characteristics in the relapse rather than in the primary tumour.

The first approach in palliative therapy in men with oestrogen receptor-positive tumours is hormonal therapy with tamoxifen with an approximate $50 \%$ response rate [49]. Use of $\mathrm{Al}$ is still doubtful in men, but in one report three out of five male patients had stable disease after treatment with anastrozole [52]. Benefit of letrozole in recurrent metastatic disease has also been reported [53].

$\mathrm{Al}$, when treating males, should probably better be used in combination with a GnRH analogue [52]. Fulvestrant, a pure anti-oestrogen, has been reported to have effect in two cases of MBC [7]. Chemotherapy for metastatic disease should of course be offered at first relapse to males with a receptor-negative disease and/or for those with biologically aggressive disease and can provide significant palliation. Patients who have developed a hormone-resistant metastatic disease should also be offered systemic chemotherapy and trastuzumab in Her-2/neu-positive cases could be considered.

\section{Acknowledgements}

Sources of support in the form of grants are gratefully appreciated from the Swedish Cancer Society, the Swedish Research Council, Linné Grant, the research funds at Radiumhemmet, ALF/ FoUU grants.

\section{References}

1. Fentiman IS, Fourquet $A$, Hortobagyi GN. Male breast cancer. Lancet 2006; 367: 595-604.

2. Giordano SH, Buzdar AU, Hortobagyi GN. Breast cancer in men. Ann Intern Med 2002; 137: 678-687.

3. Giordano SH, Cohen DS, Buzdar AU, Perkins G, Hortobagyi GN. Breast carcinoma in men: a population-based study. Cancer 2004; 101: 51-57.

4. Malani AK. Male breast cancer: a different disease than female breast cancer? South Med J 2007; 100: 197.

5. Nahleh ZA, Srikantiah R, Safa M, et al. Male breast cancer in the veterans affairs population: a comparative analysis. Cancer 2007; 109: 1471-1477.

6. Czene K, Bergqvist J, Hall P, Bergh J. How to treat male breast cancer. The Breast; 2007.

7. Agrawal A, Ayantunde AA, Rampaul R, Robertson JF. Male breast cancer: a review of clinical management. Breast Cancer Res Treat 2007; 103: 11-21. 
8. Anderson WF, Althuis MD, Brinton LA, Devesa SS. Is male breast cancer similar or different than female breast cancer? Breast Cancer Res Treat 2004; 83: 77-86.

9. Goss PE, Reid C, Pintilie M, Lim R, Miller N. Male breast carcinoma: a review of 229 patients who presented to the Princess Margaret Hospital during 40 years: 1955-1996. Cancer 1999; 85: 629-639.

10. Crew KD, Neugut Al, Wang X, et al. Racial disparities in treatment and survival of male breast cancer. $J$ Clin Oncol 2007; 25: 1089-1098.

11. Giordano SH. A review of the diagnosis and management of male breast cancer. Oncologist 2005; 10: 471-479.

12. Struewing JP, Brody LC, Erdos MR, et al. Detection of eight BRCA1 mutations in 10 breast/ovarian cancer families, including 1 family with male breast cancer. Am J Hum Genet 1995; 57: 1-7.

13. Cutuli B. Strategies in treating male breast cancer. Expert Opin Pharmacother 2007; 8: 193-202.

14. Culell P, Solernou L, Tarazona J, et al. Male breast cancer: a multicentric study. Breast $J$ 2007; 13: 213-215.

15. Clarke M, Collins R, Darby $\mathrm{S}$, et al. Effects of radiotherapy and of differences in the extent of surgery for early breast cancer on local recurrence and 15-year survival: an overview of the randomised trials. Lancet 2005; 366: 2087-2106.

16. Gennari R, Curigliano G, Jereczek-Fossa BA, et al. Male breast cancer: a special therapeutic problem. Anything new? (Review). Int J Oncol 2004; 24: 663-670.

17. Bear HD, Anderson S, Brown A, et al. The effect on tumor response of adding sequential preoperative docetaxel to preoperative doxorubicin and cyclophosphamide: preliminary results from National Surgical Adjuvant Breast and Bowel Project Protocol B-27. $J$ Clin Oncol 2003; 21: 4165-4174.

18. Bergh J, Jonsson PE, Glimelius B, Nygren P. A systematic overview of chemotherapy effects in breast cancer. Acta Oncol 2001; 40: 253-281.

19. Powles TJ, Hickish TF, Makris A, et al. Randomized trial of chemoendocrine therapy started before or after surgery for treatment of primary breast cancer. $J$ Clin Oncol 1995; 13: 547-552.

20. Ellis MJ. Neoadjuvant endocrine therapy for breast cancer: medical perspectives. Clin Cancer Res 2001; 7: 4388s-4391s, discussion 4411s-4412s.

21. Smith IE, Dowsett M, Ebbs SR, et al. Neoadjuvant treatment of postmenopausal breast cancer with anastrozole, tamoxifen, or both in combination: the Immediate Preoperative Anastrozole, Tamoxifen, or Combined with Tamoxifen (IMPACT) multicenter double-blind randomized trial. J Clin Oncol 2005; 23: 5108-5116.

22. Buzdar AU, Ibrahim NK, Francis D, et al. Significantly higher pathologic complete remission rate after neoadjuvant therapy with trastuzumab, paclitaxel, and epirubicin chemotherapy: results of a randomized trial in human epidermal growth factor receptor 2-positive operable breast cancer. J Clin Oncol 2005; 23: 3676-3685.
23. Cutuli B, Lacroze M, Dilhuydy JM, et al. Male breast cancer: results of the treatments and prognostic factors in 397 cases. Eur J Cancer 1995; 31A: 1960-1964.

24. Donegan WL, Redlich PN, Lang PJ, Gall MT. Carcinoma of the breast in males: a multiinstitutional survey. Cancer 1998; 83: 498-509.

25. Stierer M, Rosen $\mathrm{H}$, Weitensfelder W, et al. Male breast cancer: Austrian experience. World J Surg 1995; 19: 687-692, discussion 683-692.

26. Salvadori B, Saccozzi R, Manzari A, et al. Prognosis of breast cancer in males: an analysis of 170 cases. Eur $J$ Cancer 1994; 30A: 930-935.

27. Ribeiro G, Swindell R. Adjuvant tamoxifen for male breast cancer (MBC). Br J Cancer 1992; 65: 252-254.

28. Patel HZ, Buzdar AU, Hortobagyi GN. Role of adjuvant chemotherapy in male breast cancer. Cancer 1989; 64: 1583-1585.

29. Yildirim E, Berberoglu U. Male breast cancer: a 22-year experience. Eur J Surg Oncol 1998; 24: 548-552.

30. Ribeiro G. Male breast carcinoma - a review of 301 cases from the Christie Hospital \& Holt Radium Institute, Manchester. Br J Cancer 1985; 51: 115-119.

31. Donegan WL, Redlich PN. Breast cancer in men. Surg Clin North Am 1996; 76: 343-363.

32. Anelli TF, Anelli A, Tran KN, Lebwohl DE, Borgen PI. Tamoxifen administration is associated with a high rate of treatment-limiting symptoms in male breast cancer patients. Cancer 1994; 74: 74-77.

33. Howell A, Cuzick J, Baum M, et al. Results of the ATAC (Arimidex, Tamoxifen, Alone or in Combination) trial after completion of 5 years' adjuvant treatment for breast cancer. Lancet 2005; 365: 60-62.

34. Coates AS, Keshaviah A, Thurlimann B, et al. Five years of letrozole compared with tamoxifen as initial adjuvant therapy for postmenopausal women with endocrineresponsive early breast cancer: update of study BIG 1-98. J Clin Oncol 2007; 25: 486-492.

35. Coombes RC, Kilburn LS, Snowdon CF, et al. Survival and safety of exemestane versus tamoxifen after 2-3 years' tamoxifen treatment (Intergroup Exemestane Study): a randomised controlled trial. Lancet 2007; 369: 559-570.

36. Mauras N, O'Brien KO, Klein KO, Hayes V. Estrogen suppression in males: metabolic effects. $J$ Clin Endocrinol Metab 2000; 85: 2370-2377.

37. Giordano $\mathrm{SH}$, Hortobagyi GN. Leuprolide acetate plus aromatase inhibition for male breast cancer. J Clin Oncol 2006; 24: e42-43.

38. Bagley CS, Wesley MN, Young RC, Lippman ME. Adjuvant chemotherapy in males with cancer of the breast. Am J Clin Oncol 1987; 10: 55-60.

39. Giordano SH, Perkins GH, Broglio K, et al. Adjuvant systemic therapy for male breast carcinoma. Cancer 2005; 104: 2359-2364.

40. Walshe JM, Berman AW, Vatas U, et al. A prospective study of adjuvant CMF in males with node positive breast cancer: 20-year follow-up. Breast Cancer Res Treat 2007; 103: 177-183.

41. Ravandi-Kashani F, Hayes TG. Male breast cancer: a review of the literature. Eur $J$ Cancer 1998; 34: 1341-1347. 
42. Rudlowski C, Friedrichs N, Faridi A, et al. Her-2/neu gene amplification and protein expression in primary male breast cancer. Breast Cancer Res Treat 2004; 84: 215-223.

43. Wang-Rodriguez J, Cross K, Gallagher S, et al. Male breast carcinoma: correlation of ER, PR, Ki-67, Her2$\mathrm{Neu}$, and p53 with treatment and survival, a study of 65 cases. Mod Pathol 2002; 15: 853-861.

44. Rayson D, Erlichman C, Suman VJ, et al. Molecular markers in male breast carcinoma. Cancer 1998; 83: 1947-1955.

45. Tanner M, Isola J, Wiklund $\mathrm{T}$, et al. Topoisomerase Ilalpha gene amplification predicts favorable treatment response to tailored and dose-escalated anthracyclinebased adjuvant chemotherapy in Her-2/neu-amplified breast cancer: Scandinavian Breast Group Trial 9401. J Clin Oncol 2006; 24: 2428-2436.

46. Slamon DJ, Leyland-Jones B, Shak S, et al. Use of chemotherapy plus a monoclonal antibody against HER2 for metastatic breast cancer that overexpresses HER2. N Engl J Med 2001; 344: 783-792.

47. Marty M, Cognetti F, Maraninchi D, et al. Randomized phase II trial of the efficacy and safety of trastuzumab combined with docetaxel in patients with human epidermal growth factor receptor 2-positive metastatic breast cancer administered as first-line treatment: the M77001 study group. J Clin Oncol 2005; 23: 4265-4274.

48. Piccart-Gebhart MJ, Procter M, Leyland-Jones B, et al. Trastuzumab after adjuvant chemotherapy in HER2positive breast cancer. $N$ Engl $J$ Med 2005; 353: 1659-1672.

49. Jaiyesimi IA, Buzdar AU, Sahin AA, Ross MA. Carcinoma of the male breast. Ann Intern Med 1992; 117: 771-777.

50. Franco A, Chlebowski F. Discordance in estrogen (ER) and progesteron (PR) status between primary metastatic breast cancer: a meta-analysis. In: Perry M (ed.). 40th Annual Meeting of the ASCO, New Orleans, LA, 2004.

51. Gancberg D, Di Leo A, Cardoso F, et al. Comparison of HER-2 status between primary breast cancer and corresponding distant metastatic sites. Ann Oncol 2002; 13: 1036-1043.

52. Giordano SH, Valero V, Buzdar AU, Hortobagyi GN. Efficacy of anastrozole in male breast cancer. Am J Clin Oncol 2002; 25: 235-237.

53. Italiano A, Largillier R, Marcy PY, et al. Complete remission obtained with letrozole in a man with metastatic breast cancer. Rev Med Interne 2004; 25: 323-324. 